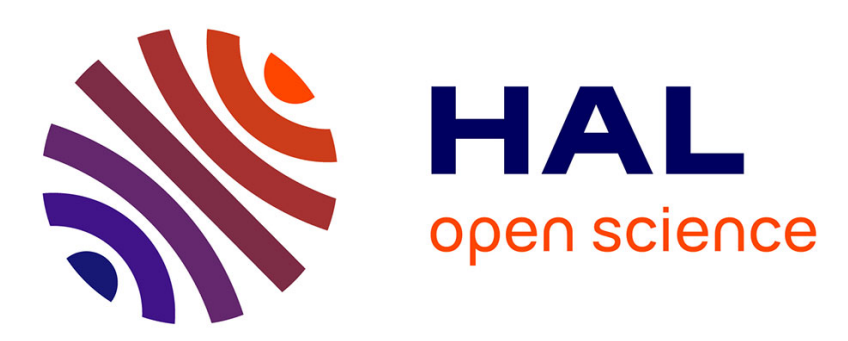

\title{
Streptococcal pyrogenic exotoxin B (SpeB) boosts the contact system via binding of alpha-1 antitrypsin
}

Louise Meinert Niclasen, Johan G. Olsen, Robert Dagil, Zhang Qing, Ole E Sørensen, Birthe B. Kragelund

\section{- To cite this version:}

Louise Meinert Niclasen, Johan G. Olsen, Robert Dagil, Zhang Qing, Ole E Sørensen, et al.. Streptococcal pyrogenic exotoxin B (SpeB) boosts the contact system via binding of alpha-1 antitrypsin. Biochemical Journal, 2011, 434 (1), pp.123-132. 10.1042/BJ20100984 . hal-00560689

\section{HAL Id: hal-00560689 \\ https://hal.science/hal-00560689}

Submitted on 29 Jan 2011

HAL is a multi-disciplinary open access archive for the deposit and dissemination of scientific research documents, whether they are published or not. The documents may come from teaching and research institutions in France or abroad, or from public or private research centers.
L'archive ouverte pluridisciplinaire HAL, est destinée au dépôt et à la diffusion de documents scientifiques de niveau recherche, publiés ou non, émanant des établissements d'enseignement et de recherche français ou étrangers, des laboratoires publics ou privés. 


\section{Streptococcal pyrogenic exotoxin B (SpeB) boosts the contact system via binding of alpha-1 antitrypsin}

Louise Meinert Niclasen"1, Johan G. Olsen ${ }^{1}$, Robert Dagil ${ }^{1}$, Zhang Qing ${ }^{2}$, Ole E. Sørensen ${ }^{2 *}$, Birthe B. Kragelund ${ }^{1 *}$

${ }^{1}$ University of Copenhagen, Department of Biology, Structural Biology and NMR Laboratory, Ole Maaloes Vej 5, DK-2200 Copenhagen N, Denmark

${ }^{2}$ Lund University, Department of Clinical Sciences, Division of Infection Medicine, BMC, B14, Tornavägen 10, SE-221 84 Lund, Sweden

${ }^{*}$ Corresponding authors

E-mail: bbk@bio.ku.dk

E-mail: Ole_E.Sorensen@med.lu.se

Short (page heading) running title: SpeB enhances bacterial killing 


\section{SYNOPSIS}

The Streptococcus pyogenes cysteine protease, SpeB, is important for the invasive potential of the bacteria, but its production is down-regulated following systemic infection. This prompted us to investigate if SpeB potentiated the host immune response after systemic spreading. Addition of SpeB to human plasma increased plasma-mediated bacterial killing and prolonged coagulation time through the intrinsic pathway of coagulation. This effect was independent of the enzymatic activity of SpeB and was mediated by a non-covalent medium-affinity binding and modification of the serpin alpha-1 antitrypsin. Consequently, supplement of alpha-1 antitrypsin to plasma increased bacterial survival. Sequestration of alpha-1 antitrypsin by SpeB led to enhanced contact system activation, supported by increased bacterial growth in prekallikrein deficient plasma. In a mouse model of systemic infection administration of SpeB significantly reduced bacterial dissemination. The findings reveal an additional layer of complexity to host-microbe interactions which may be of benefit in treatment of severe bacterial infections.

Keywords: dissemination, innate immune system, photo cross-linking, Streptococcus pyogenes, systemic spreading 


\section{INTRODUCTION}

The Group A Streptococci (GAS) Streptococcus Pyogenes is a common bacterial pathogen. For the past two decades, several studies have reported an increase in the severity and the incidence of GAS infections in humans [1]. In addition to infections of the upper respiratory tract and the skin, GAS causes a wide variety of invasive systemic infections, with two potentially serious complications: acute rheumatic fever and acute glomerulonephritis [2, 3]. Recently, infection with GAS has reemerged as an important cause of toxic shock syndrome, as well as life-threatening skin and soft tissue infections, especially necrotizing fasciitis due to a phenotypic shift to a more invasive phenotype [4]. Due to cases of rapidly progressive disease with untreatable outcome, this pathogen remains a major concern [1].

GAS owes its fundamental success as a pathogen to its ability to colonize and rapidly multiply and spread in its host while evading phagocytosis and circumventing the immune system [5,6]. The membrane of GAS contains antigens similar to those of mammalian muscle and connective tissue [7-9] which provides a molecular mimicry that results in a corresponding tolerant or even suppressed immune response by the host. In combination with the actions of various virulence factors, GAS has the ability to evade the immune system. One of these factors is the cysteine protease streptococcal pyrogenic exotoxin B (SpeB). During infection it degrades a range of proteins important for the immune response of the host such as immunoglobulins and antimicrobial (or host defense) peptides as well as integrins [10-12].

SpeB is secreted by the pathogen as an extracellular zymogen with a molecular weight of $40 \mathrm{kDa}$. Through limited proteolysis the zymogen can be converted into the active, mature enzyme (mSpeB) by removal of the $118 \mathrm{~N}$-terminal residues [13]. The three-dimensional structure of an inactive mutant form of the zymogen has been solved [14] and has revealed the protease to belong to the papain-like family of cysteine proteases. Recently two structures of the mature enzyme, $\mathrm{mSpeB}$, were solved, one in a monomeric, inactive state [15] and one with a bound inhibitor revealing a dimeric active conformation [16].

Although several regulators of SpeB transcription are reported, i.e. CovR, Vfr and RopB [17-19], the regulation of SpeB gene expression is complex and incompletely understood. SpeB causes increased severity and spreading of GAS infection in mouse models and it is apparent that the bacterial protease SpeB is mandatory for the initial invasion process [20-22]. The fact that SpeB is down-regulated after systemic spreading [23] suggests that its presence after invasion may hamper or even inhibit the survival of the bacteria in the host. Indeed, an exposure to human blood or inflammatory fluid from skin chambers lead to decreased expression of SpeB [24, 25]. 
In this study we found that human plasma severely affected SpeB production in S. pyogenes. Addition of purified, enzymatically inactive mature SpeB caused increased bacterial killing in human plasma. This increased killing was mediated by the binding of SpeB to alpha-1-antitrypsin (A1AT) that consequently led to increased activity of an $a$ priori activated contact system-mediated bacterial killing. These findings were corroborated in a mouse model of systemic infection where inter-peritoneal administration of SpeB significantly decreased bacterial dissemination in vivo.

\section{MATERIALS AND METHODS}

Bacteria and culturing conditions

The S. Pyogenes strain AP1 of serotype M1 strain 40/58 was obtained from the World Health Organization Collaborating Centre for Reference and Research on Streptococci, Prague, Czech Republic. The S. Pyogenes strain Alab49 was provided by Debra E. Messen, New York Medical College. Bacteria were grown in Todd-Hewitt broth (BD Biosciences) in $5 \%(\mathrm{v} / \mathrm{v}) \mathrm{CO}_{2}$ at $37^{\circ} \mathrm{C}$ with added yeast extract.

Purification of SpeB

For purification of mSpeB, the S. pyogenes strain Alab49 was grown for 48-60 hours in Todd-Hewitt broth (BD Biosciences) with $0.2 \%(\mathrm{w} / \mathrm{w})$ yeast extract (Difco) in $5 \%(\mathrm{v} / \mathrm{v})$ $\mathrm{CO}_{2}$ at $37^{\circ} \mathrm{C}$. The bacteria were pelleted by centrifugation at $3000 \mathrm{xg}$ for $20 \mathrm{~min}$ at $4^{\circ} \mathrm{C}$ and the supernatant sterile filtered. The filtrate was subjected to ammonium sulfate precipitation $(80 \%(\mathrm{w} / \mathrm{v}))$. The resulting pellet was dissolved in MilliQ water to a volume of $50 \mathrm{ml}$ and subjected to dialysis $\mathrm{O} / \mathrm{N}$ at $4^{\circ} \mathrm{C}$ against $20 \mathrm{mM}$ sodium acetate buffer $\mathrm{pH}$ 5. The protein sample was centrifuged at $20000 \mathrm{x}$ for $20 \mathrm{~min}$ at $4^{\circ} \mathrm{C}$ and the supernatant applied to a $5 \mathrm{ml}$ HiTrap SP FF anion exchange column (GE Healthcare) equilibrated in $20 \mathrm{mM}$ sodium acetate $\mathrm{pH}$. The protein was eluted with $0-2 \mathrm{M} \mathrm{NaCl}$ in a gradient over 20 column volumes $(\mathrm{CV})$ and eluted at $0.15 \mathrm{M} \mathrm{NaCl}$ at a flow of 5 $\mathrm{ml} / \mathrm{min}$. The eluted protein was further purified on a G75 Sephadex gelfiltration column $(1.6 \times 86 \mathrm{~cm})$ using a $20 \mathrm{mM}$ sodium acetate, $150 \mathrm{mM} \mathrm{NaCl}$ buffer $\mathrm{pH}$ 5. The protein eluted after $90 \mathrm{ml}$ at a flow of $0.5 \mathrm{ml} / \mathrm{min}$. When produced natively, $\mathrm{mSpeB}$ is inhibited by E64 originating from the growth media and the inhibitor is covalently attached to the active site cysteine [16].

\section{Fractionation of human citrate plasma}

An aliquot of $30 \mathrm{ml}$ of human citrate plasma received from the blood bank at Rigshospitalet, Copenhagen, Denmark, was subjected to gel filtration at $4^{\circ} \mathrm{C}$ on a G200 Sephadex column $(5 \times 70 \mathrm{~cm})$ with a bed volume of $1374 \mathrm{~mL}$ using a PBS buffer, $\mathrm{pH}$ 7.4. 
The plasma proteins were collected in four different pools according to protein size (denoted plasma pool 1-4).

In vitro infection assay

For the antibacterial assay AP1 bacteria were grown $\mathrm{O} / \mathrm{N}$ in $\mathrm{TH}$ medium in $5 \%(\mathrm{v} / \mathrm{v})$ $\mathrm{CO}_{2}$ at $37^{\circ} \mathrm{C}$. The bacteria were subsequently diluted to $\mathrm{A}_{620}=0.5$ in TH-medium, plasma or plasma with added trans-Epoxysuccinyl-L-leucylamido (4-guanidino) butane (E64) inhibited $(10 \mu \mathrm{M}) \mathrm{mSpeB}$ or equal amounts of PBS (v/v) or with added A1AT $(0.64$ $\mathrm{mg} / \mathrm{ml})$. Freshly frozen plasma from healthy individuals was obtained from the blood bank at Lund University Hospital, Lund, Sweden, and kept frozen at $-80^{\circ} \mathrm{C}$ until use. The in vitro infection assay was also performed in plasma deficient in contact factors obtained from King George Hospital and with the addition of A1AT ( $8 \mu \mathrm{l}$ of $20 \mathrm{mg} / \mathrm{ml}$ added to a total of $253 \mu \mathrm{l}$; [A1AT] final $=14 \mu \mathrm{M})$. At different time points, growth was measured by plating appropriate dilutions of the bacterial suspension on $\mathrm{TH}$ agar plates. Plates were incubated overnight in $5 \%(\mathrm{v} / \mathrm{v}) \mathrm{CO}_{2}$ at $37^{\circ} \mathrm{C}$ and the number of $\mathrm{CFU}$ was determined by counting the number of formed colonies. To maintain proper growth of the bacteria when performing the antibacterial assay with the plasma pools obtained from gel filtration of whole plasma, $50 \mu \mathrm{l}$ 5xTHY-media was added to each reaction (total volume $250 \mu \mathrm{l}$ ).

\section{Chemical cross-linking and protein identification}

Chemical cross-linking was performed using ProFound Label Transfer sulfosuccinimidyl-2-[6-(biotinamido)-2-(p-azidobenzamido)-hexanoamido]-ethyl-1,3'dithioproprionate (SBED) protein-protein interaction reagent (Pierce Biotechnology). All steps were performed in the dark. In a volume of $0.3 \mathrm{~mL}, 0.19 \mathrm{mM} \mathrm{mSpeB}$ and 1.9 $\mathrm{mM}$ sulfo-SBED (dissolved initially in DMSO) were incubated in the dark at room temperature for $30 \mathrm{~min}$ with continuous rotation. The reaction mixture was dialyzed against $0.5 \mathrm{~L}$ of $50 \mathrm{mM}$ HEPES, $150 \mathrm{mM} \mathrm{NaCl} \mathrm{pH} \mathrm{7.4} \mathrm{O/N}$ in the dark at $4^{\circ} \mathrm{C}$. After dialysis the sample was mixed directly with the different prey proteins in a minimum of ten excess volumes for $60 \mathrm{~min}$ followed by photolysis at $365 \mathrm{~nm}$ for $30 \mathrm{~min}$.

Cross-linked samples were analyzed by SDS-PAGE on 15\% (v/v) Tris-Glycin gels (Lonza) under reducing (100 $\mathrm{mM}$ dithiothreitol) and non-reducing conditions. Detection of biotinylated samples was performed by Western blotting using horseradish peroxidase (HRP)-labeled streptavidin diluted 1:5000. The band corresponding to the positive Western signal was excised from an identical, but silver stained SDS-PAGE gel and protein identification performed by trypsin digestion followed by mass spectrometry at Alphalyse A/S (Denmark). A1AT was obtained from Cell Sciences to a purity of $>95 \%$ and using the procedure above, analyzed by Western blot.

\section{Clotting assay}


Coagulation time of human citrate plasma was determined in an Amelung KC4A micro coagulometer. An aliquot of $100 \mu \mathrm{l}$ of untreated human citrated plasma (from the blood bank at Lund University Hospital, Lund, Sweden) was incubated with mSpeB at varying concentrations (from 0 to $18 \mu \mathrm{M}$ ) for 1 hour at RT. To analyze the intrinsic pathway of coagulation, $50 \mu \mathrm{l}$ of a kaolin-solution (Technoclone) was added to the incubated sample, pre-heated for $60 \mathrm{~s}$ at $37^{\circ} \mathrm{C}$ and clotting initiated by adding $50 \mu \mathrm{l}$ of a $30 \mathrm{mM} \mathrm{CaCl}_{2}$ solution. To analyze the extrinsic pathway of coagulation $100 \mu \mathrm{L}$

Thrombomax with calcium (PT reagent; Sigma-Aldrich) was added to $300 \mu \mathrm{L}$ of preheated plasma.

\section{Determination of $K_{d}$ using fluorescence spectroscopy}

The interaction between $\mathrm{mSpeB}$ and A1AT was investigated using fluorescence spectroscopy measuring emission at 305-400 nm with excitation at either $280 \mathrm{~nm}$ or 296 $\mathrm{nm}$. Throughout the experiment E64 inhibited $\mathrm{mSpeB}$ was used. An emission spectrum of a $10 \mu \mathrm{M}$ mSpeB sample was recorded and added to each recorded spectrum on a series of A1AT samples with varying concentration from $0-100 \mu \mathrm{M}$. The emission spectra for the same series of concentrations of A1AT now in complex with $10 \mu \mathrm{M}$ mSpeB were also recorded. All spectra were recorded in PBS buffer pH 7.4 at RT. The summed emission spectrum of $10 \mu \mathrm{M}$ mSpeB and a varied amount of A1AT were compared to the emission spectrum of the corresponding sample of the complex. The differences between these two spectra (f280nm [A1AT:mSpeB $\left.]_{\text {cplx }}-f_{280 n m}[\mathrm{mSpeb}+\mathrm{A} 1 \mathrm{AT}]_{\text {summed }}\right)$ were plotted against the concentration of A1AT. The dissociation constant, $K_{d}$, between $\mathrm{A} 1 \mathrm{AT}$ and $\mathrm{mSpeB}$ was determined from non-linear least squares fitting to the following equation describing one single binding site $\left(Y=\left(B \max { }^{*} \mathrm{x}\right) /\left(\mathrm{K}_{\mathrm{d}}+\mathrm{x}\right)\right)$ using GraphPad Prism 4 [26].

Systemic S. pyogenes infection in mice

The systemic spread of bacteria in vivo was investigated using a mouse model of intraperitoneal infection. A total of 24 male Balb/C mice 8-11 weeks of age were injected i.p. with $S$. pyogenes AP1 bacteria $\left(1 \times 10^{6} \mathrm{CFU}\right)$, followed by i.p. injection of an equal volume of either PBS with added E64 $(n=12)$ or of $50 \mu \mathrm{g} / \mathrm{animal}$ E64 inhibited mSpeB $(\mathrm{n}=12)$. The mice were sacrificed 18 hours after the last injection. The spleen was excised and the total number of CFU in the spleen determined by serial dilution on blood agar plates. The P-value was determined using the two-tailed paired t-test.

Stimulation of mononuclear cells (lymphocytes and monocytes)

Blood was collected from a healthy volunteer. After sedimentation with 2\% Dextran T500 (Amersham Pharmacia Biotech, Uppsala, Sweden) in isotonic $\mathrm{NaCl}$, the leukocyterich supernatant was pelleted and resuspended in saline for subsequent centrifugation on Lymphoprep (Nycomed Pharma A/S, Oslo, Norway) at $400 \times \mathrm{g}$ for 30 minutes. The 
mononuclear cells were collected in the supernatant following centrifugation. The cells were washed twice in sterile $0.9 \% \mathrm{NACl}$ and resuspended in Iscove's Modified Dulbecco's Medium (Invitrogen, Carlsbad, CA) with 10\% autologous serum and antibiotic-antimycotic solution (Invitrogen). The cells were stimulated using $10 \mu \mathrm{g} / \mathrm{ml}$ peptidoglycan (Sigma) or $10 \mu \mathrm{g} / \mathrm{ml}$ E64 inhibited mSpeB. Medium was harvested after four days. IL-8 secretion was examined by Western Blots and IL-6 secretion by IL-6 ELISA (R\&D Systems).

\section{Isolation of polymorphonuclear neutrophils (PMN)}

PMN were isolated at $4^{\circ} \mathrm{C}$ from blood from healthy donors using gradient centrifugation [27]. EDTA-stabilized whole blood $(5 \mathrm{~mL})$ was placed on $3 \mathrm{~mL}$ Polymorfprep (Nycomed A/S, Oslo, Norway) and centrifuged for $35 \mathrm{~min}$ at $400 \mathrm{xg}$. The granulocyte layer was harvested and resuspended in Hanks' Buffered Salt Solution (HBSS) (Gibco, Life Technologies Inc., Rockville, MD), washed three times and centrifuged for $7 \mathrm{~min}$ at $200 \times \mathrm{g}$. PMN were then resuspended $\left(2.0 \times 10^{6}\right.$ cells $\left./ \mathrm{mL}\right)$ in HBSS with 0.2\% HSA (Behring, Marburg, Germany).

\section{Chemotaxis}

Neutrophil chemotaxis was assessed as previously described (Nybo et al., 1998). Briefly, a 48 well microchemotaxis chamber (NeuroProbe Inc., Gaithersburg, MD) with $3 \mu \mathrm{m}$ Millipore filters, type SS (Millipore Corp., Billerica, MA), was used. SpeB $(2 \mu \mathrm{g} / \mathrm{ml}$ and $0.4 \mu \mathrm{g} / \mathrm{ml}$ ) was tested as chemattractant with $\mathrm{N}$-formyl-methionyl-leucyl-phenylalanine (fMLP) $\left(10^{-8} \mathrm{~mol} / \mathrm{L}\right)$ as a positive chemoattractant control. PMN were placed in the microchemotaxis chamber for $30 \mathrm{~min}$ at $37^{\circ} \mathrm{C}$, and directed migration was subsequently measured by the leading-front principle (Zigmond and Hirsch, 1972) with three cells per high power field. Three fields were read per well, and all samples were assayed in duplicate. All migration distances were subtracted the spontaneous migration measured in non-stimulated PMN and expressed as $\mu \mathrm{m}$ per $30 \mathrm{~min}$.

\section{RESULTS}

Systemic spreading of bacteria from sites of entry requires invasion into blood circulation. It was previously found that exposure to inflammatory tissue fluids and blood down-regulated the expression of SpeB from bacteria in vitro [28]. Consequently, we investigated the effect of human plasma on SpeB production from S. pyogenes. Bacteria were grown to stationary phase (overnight) in THY media with or without addition of human plasma. In contrast to whole human plasma [29], 20\% plasma in THY medium did not inhibit bacterial growth compared to growth in THY medium alone as judged from OD measurements. Accordingly, both bacteria in THY and THY 
with $20 \%$ plasma had reached stationary phase after over night culture. After ODnormalization, $\mathrm{mSpeB}$ production/secretion were investigated by Western blot (Figure 1). No SpeB could be detected in the growth medium when the bacteria were exposed to plasma. Similar results were found when bacteria were grown in the presence of the covalently linked cysteine protease inhibitor E64, showing that the plasma dependent down-regulation was independent of the enzymatic activity of SpeB. Control experiments demonstrated further that incubation of $\mathrm{mSpeB}$ in $20 \%(\mathrm{v} / \mathrm{v})$ plasma for 24 hours at $37^{\circ} \mathrm{C}$ did not cause degradation of the protein (data not shown). Accordingly, exposure to plasma inhibits SpeB production by S. pyogenes.

\section{mSpeB mediates decreased bacterial proliferation in human plasma in vitro}

Whole human plasma impairs the growth of $S$. pyogenes as a result of activation of the contact system resulting in decreased bacterial dissemination in vivo [29]. Accordingly, we tested whether the mature form of SpeB (mSpeB) influenced the survival of $S$. pyogenes in whole human plasma. The addition of E64-inhibited mSpeB significantly reduced the growth of $S$. pyogenes strain AP1 $(\mathrm{p}<0.05)$ in human plasma (Figure 2(A)) compared to growth in plasma without mSpeB. No effect of E64-inhibited mSpeB was seen on growth in TH medium alone. To eliminate a possible dilution effect on growth an equal volume of PBS buffer was added to plasma. This had no influence on the bacterial growth rate (data not shown). Likewise, the effect of the inhibitor E64 on bacterial growth was evaluated. Neither in the presence or absence of $20 \%(\mathrm{v} / \mathrm{v})$ plasma did E-64 inhibit bacterial growth (data not shown).

To explore if the antibacterial effect was mediated by the contact system as noted before [30], the influence of E64-inhibited $\mathrm{mSpeB}$ on bacterial growth in kallikrein deficient plasma was investigated. Normally during activation of the contact system kallikrein degrades high molecular weight kininogen (HMWK) which results in libration of antimicrobial peptides [29]. Addition of E64-inhibited mSpeB to prekallikrein deficient plasma did not reduce bacterial growth (Figure 2(B)). Thus, the effect of E64-inhibited mSpeB on bacterial killing in plasma was mediated via the contact system of the host.

\section{SpeB binds to A1AT in human plasma}

To identify any possible components in human plasma that could be responsible for mediating the $\mathrm{mSpeB}$ antibacterial effect, citrate plasma was fractionated by size exclusion chromatography and collected in four pools in PBS (pH 7.4). These four pools (denoted pools 1-4) as well as double-combinations thereof were all tested for their effect on the growth of the S. pyogenes strain AP1 with and without addition of E64inhibited mSpeB (Figure 3). 
Growth inhibition studies using the four pools without addition of mSpeB showed that they all inhibited growth to some extend compared to growth in $\mathrm{TH}$. The inhibitory potential of pool 4 was the weakest and pool 1 the strongest (Figure 3A). E64inhibited mSpeB had no effect on growth by itself (TH vs TH+mSpeB, pool 1,2 and 3), but had a significant negative effect in combination with whole plasma as well as in combination with pool 4 . No significant effect of $\mathrm{mSpeB}$ was observed when added to pool 1. Interestingly, the inhibitory effect of pool 1 alone is larger than the sum of the inhibitory potential of the individual pools. This indicates that there must be a combined effect such that the inhibitory effect of pool 1 is moderated by proteins in one of the other pools (cross-pool interaction and/or common growth inhibiting targets)

From these data we hypothesized the presence of an inhibitor of a growth inhibitory factor in plasma and that this inhibitor could be impeded by E64-mSpeB resulting in reduced growth. Therefore, the effect on growth of S. pyogenes in the presence of different combinations of pools 1 - 4 with and without the addition of E64mSpeB was tested. From these studies it was seen that Pool 4 contained the factor(s) suppressing the growth inhibitory strength of pool 1 while E64-mSpeB, at least in part, abolished this suppression (pool $(1+4)$ vs pool $(1+4)+\mathrm{mSpeB}$ ).

Obviously, many plasma factors influence bacterial growth in a much more complex manner than delineated here. Therefore, to pin-point the role of $\mathrm{mSpeB}$ in growth inhibition, an experiment to detect possible $\mathrm{mSpeB}$ interaction partners was performed. mSpeB was coupled to the chemical photo cross-linker sulfosuccinimidyl-2-[6(biotinamido)-2-(p-azidobenzamido)-hexanoamido]-ethyl-1,3'-dithioproprionate (SBED). This chemical cross-linker connects by photolysis mSpeB covalently to the interacting molecule and the complex it detectable via a biotin label. Under reducing conditions, the linker is broken and the biotin label stays attached to the interacting molecule. Based on the antibacterial assay, proteins of plasma pool 4 were initially used as prey proteins. Following chemical labeling and photo cross-linking the subsequent Western blot analysis only revealed a single interaction partner (Figure 4(A)). To confirm that only one protein in human plasma interacted with $\mathrm{mSpeB}$ and rule out any interaction partners not present in pool 4, the same cross-linking experiment was performed with whole human plasma. This experiment resulted in the presence of two bands on a Western blot (Figure 4(B), lane 1 and 2), demonstrating a high level of specificity of the interaction. The upper (major) band corresponded in size to the obseryed pool 4 band.

In order to test whether the interaction between the two proteins was a result of the chemical nature of the photo cross-linker itself, the intrinsically disordered yeast protein Spd1 [31] was SBED-labeled and incubated with plasma. No bands appeared on the resulting Western blot and no interaction had been mediated solely by the cross- 
linker confirming that it was not the label itself that was responsible for the affinity of SpeB for the observed interaction partner (Figure 4(B), lane 3).

Analysis of the protein located in the band on the gel corresponding to the positive Western band from pool 4 resulted in identification by trypsin-MS-analysis of two proteins, human albumin and alpha-1 antitrypsin (A1AT). For albumin the sequence coverage was $37 \%$. For A1AT the protein identification revealed an overall sequence coverage of $49 \%$, covering both the $\mathrm{N}$ - and C-terminal ends of the protein as well as the central part. Albumin and A1AT are known to co-migrate on SDS-PAGE [32], so it is likely that the complexes superpose on the gel. Albumin is an abundant plasma protein that interacts with a broad spectrum of endogenous compounds [33]. Furthermore, albumin is a known substrate of SpeB [34]. Since the sequence identification of A1AT also comprised the C-terminal part, A1AT was not necessarily interacting with SpeB in a suicidal mechanism which normally leads to cleavage of the C-terminal part of A1AT.

Interactions with albumin and A1AT were both confirmed by cross-linking of the SBED-labeled $\mathrm{mSpeB}$ to isolated, commercially obtained proteins. Western blot analysis of A1AT pre-incubated with SBED-labeled $\mathrm{mSpeB}$ resulted in a dominant high intensity band at $50 \mathrm{kDa}$ as well as a lower intensity band at $40 \mathrm{kDa}$ (Figure 4(C)). Albumin interaction was confirmed by the same method (data not shown). The low intensity band of A1AT corresponded in size to cleaved A1AT which was shown to be present in the commercial preparation. Consequently, mSpeB interacted with intact as well as activated (and cleaved) A1AT.

\section{mSpeB binds A1AT non-covalently}

Normally when A1AT binds its substrate a cleavage of the C-terminal tail of A1AT occurs and a covalent bond is formed between A1AT and its substrate [35, 36]. To evaluate the nature of the interaction between A1AT and mSpeB, A1AT was incubated with E64-inhibited mSpeB and analyzed by non-reducing SDS-PAGE (Figure 5). In clear contrast to the canonical inhibition mechanism reported for A1AT, no covalent bond formation between $\mathrm{A} 1 \mathrm{AT}$ and $\mathrm{mSpeB}$ could be observed. Instead, when a similar experiment was performed with active, uninhibited $\mathrm{mSpeB}, \mathrm{A} 1 \mathrm{AT}$ was cleaved to a size comparable to that observed in the Western blot analysis of whole human plasma (Figure 5). No high molecular weight band was observed indicating that A1AT did bind covalently to SpeB neither in the active nor in the E64 inhibited state. As a control experiment A1AT was incubated with trypsin where a covalent band was clearly formed (Figure 5). Thus, since both the intact and the cleaved form of A1AT interacted with E64-inhibited mSpeB the binding of A1AT to mSpeB occurs independently of the enzymatic activity of either protein. This suggests that the mechanism of interaction between the cysteine protease $\mathrm{mSpeB}$ and the suicidal protease inhibitor, A1AT appears to be strikingly different to what has been observed so far for most A1AT targets. 
Rather this complex may be related more to the alpha-1-PI-Pittsburg and S195A trypsin complex [37] and as such it belongs to the very few examples of reversible serpinproteinase complexes.

\section{mSpeB binds A1AT with medium affinity}

To further investigate the details of the mSpeB-A1AT binding we determined the dissociation constant, $\mathrm{K}_{\mathrm{d}}$, for the interaction between mSpeB and A1AT. The complex was initially analyzed by size-exclusion chromatography without detection of complexes (data not shown). Since this indicated a low affinity binding similar to previously observations for reversible serpin-proteinase complexes [38], the interaction was examined using fluorescence spectroscopy. Fluorescence emission spectra were recorded with excitation at $280 \mathrm{~nm}$ or $296 \mathrm{~nm}$ with the most significant changes in the emission intensity observed from excitation at $280 \mathrm{~nm}$.

By addition of the emission spectra of $\mathrm{mSpeB}$ alone $(10 \mu \mathrm{M})$ and A1AT alone (0$100 \mu \mathrm{M})$ one spectrum for each mSpeB:A1AT ratio was calculated. These summation spectra represented the unbound scenario and were compared to the spectra recorded on the mixture of the two proteins representing the complex. The difference in emission intensity at $280 \mathrm{~nm}$ was plotted against the concentration of A1AT (Figure 6). From a non-linear fit a $K_{d}$ of $29 \pm 7 \mu \mathrm{M}$ was determined. This $K_{d}$ value was measured using E64inhibited $\mathrm{mSpeB}$, and further supports that the binding of $\mathrm{mSpeB}$ to A1AT is indeed independent of the enzymatic properties of mSpeB.

The structure of mSpeB with bound inhibitor [16] has revealed that the active conformation of $\mathrm{mSpeB}$ is the dimeric state of the protein which demands larger conformational changes in the enzyme. In these studies we showed that E-64 inhibited $\mathrm{mSpeB}$ had a dimerization constant of $27 \pm 7 \mu \mathrm{M}$, which decreased to $15 \pm 7 \mu \mathrm{M}$ for uninhibited $\mathrm{mSpeB}$ [16]. No dimerization could be detected for zSpeB [16]. In light of the present results this suggests that at low enzyme concentration, A1AT may promote dimerization of $\mathrm{mSpeB}$. The Western blot from the cross-linking experiments indicated a 2:1 complex rather than to a 1:1 complex between mSpeB and A1AT (Figure 4(A), lane $5-8)$. This is in line with the fact that active $\mathrm{mSpeB}$ is a dimer. The exact stoichiometry of the mSpeB-A1AT complex will have to await further studies.

\section{A1AT binding to mSpeB boosts the contact system}

Several inhibitors of kallikrein have been reported, among those A1AT [39]. To determine the importance of A1AT as an inhibitor of the contact system, a surplus of A1AT $(0.64 \mathrm{mg} / \mathrm{ml}[14.4 \mu \mathrm{M}])$ was added to human plasma inoculated with S. pyogenes strain AP1. If sequestration of A1AT by mSpeB was the cause of the enhanced bacterial killing, addition of A1AT should thus enhance bacterial survival in plasma. Indeed, addition of $14.4 \mu \mathrm{M}$ of A1AT to human plasma significantly enhanced bacterial survival 
$(\mathrm{p}<0.05)$ (Figure 7A). Likewise, addition of A1AT to prekallikrein-free plasma had no effect on bacterial growth (Figure 7B). These findings underline not only the importance of the contact system in fighting bacterial infection in blood, but also the role of A1AT as an important inhibitor of the contact system.

\section{mSpeB prolongs coagulation time}

A1AT binds and inhibits activated protein C (APC) [40, 41]. APC acts as an anticoagulant by proteolytically inactivating factors Va and VIIIa thereby hindering the generation of thrombin $[42,43]$. A predicted consequence of mSpeB binding of A1AT in plasma would thus be an increased concentration of uninhibited APC leading to a prolonged blood coagulation time.

The effect of E-64 inhibited mSpeB on blood coagulation was monitored using an in vitro coagulation assay. The time of onset of coagulation through the contact system (or intrinsic) pathway was monitored by the addition of a kaolin-containing solution to plasma, which is a potent contact activator. A significantly prolonged coagulation time $\left.{ }^{*}=\mathrm{p}<0.05\right)$ was observed after addition of E64-inhibited mSpeB (Figure 8). Again, the effect was not a result of $\mathrm{mSpeB}$ proteolysis. Expectedly, mSpeB had no effect on the time of coagulation through the extrinsic pathway which is not influenced by A1AT (data not shown). These data demonstrate an mSpeB sequestration of A1AT that is independent of the presence of bacteria and independent of an activated contact system, and clearly demonstrates a bacterial-independent interaction between mSpeB and A1AT.

\section{SpeB decreases bacterial dissemination in vivo}

To test the effect of $\mathrm{mSpeB}$ on systemic dissemination of bacteria in vivo, a limited amount of mSpeB fully inhibited with E64 was administered intraperitoneally (i.p.) to a group of mice subsequent to i.p. injection of S. pyogenes AP1 bacteria. To rule out any proteolytic effect of the enzyme, only E64-inhibited mSpeB was administered. Dissemination of a bacterial systemic infection was significantly dampened when E-64 inhibited $\mathrm{mSpeB}$ was given to infected mice compared to controls $(\mathrm{P}=0.014$; two-tailed paired t-test), Figure 9. Importantly, no toxic effects of the inhibited mSpeB were directly evident as judged from the general well-being of the mice in accord with earlier studies on the toxicity of active mSpeB [20,21]. In the control group one mouse died. The spleen from this mouse was also dissected and the number of CFU in the spleen was determined and included in the statistical analysis mentioned above. Excluding this animal from the control group still resulted in a significant difference between the two groups of mice $(\mathrm{P}=0.027$; two-tailed paired t-test), Figure $9(\mathrm{~A})$. These data demonstrate that proteolytically inactive $\mathrm{mSpeB}$ significantly reduced bacterial dissemination in vivo. 
To test whether the effect of administration of $\mathrm{mSpeB}$ on bacterial spreading in vivo could be attributed to an increased inflammatory response, mononuclear cells were incubated with E64 inhibited $\mathrm{mSpeB}$. The response was compared to that of the cell wall component peptidoglycan (PGN), Figure 9(B). Judged from the release of IL-6 and IL-8, mSpeB was a poor proinflammatory agent compared to PGN. Chemotaxis experiments with human neutrophils demonstrated further that mSpeB was not a chemotactic factor towards human neutrophils (data not shown).

\section{DISCUSSION}

The streptococcal cysteine protease $\mathrm{mSpeB}$ is important for the invasion and survival of S. pyogenes in the human host and is known to have several immune modulating activities ensuring the successful survival of the bacteria [10, 44]. The expression of $\mathrm{mSpeB}$ appears tightly regulated and is not initiated until the bacteria enter stationary growth phase in vitro [44]. During in vivo infection mSpeB is necessary for bacterial invasion but following systemic dissemination $\mathrm{mSpeB}$ expression is down-regulated $[23,45,46]$. This indicates that after the initial invasion the continued presence of $\mathrm{mSpeB}$ may be detrimental for the bacteria.

We observed that the mature form of the cysteine protease mSpeB when fully inactivated with the covalently bound inhibitor E64 possessed the ability to enhance the endogenous antibacterial action of the contact system. This boosting of the contact system by $\mathrm{mSpeB}$ was achieved by a reversible, medium affinity binding of the promiscuous protease inhibitor A1AT, adding a novel complex to the few non-covalent serpin-complexes known so far. We observed the same non-covalent interaction between A1AT and active SpeB. The importance of this finding was underscored by in vivo experiments in mice. Dissemination of a bacterial systemic infection was significantly dampened when E64-inhibited $\mathrm{mSpeB}$ was administered to infected mice compared to controls as judged by a significantly lower number of CFU in their spleen. It has previously been shown that inhibition of the contact system enhances bacterial spreading [29]. Here we demonstrated the reverse, that enhancement of contact activation actually limits the bacterial infection.

The bacterial enzyme mSpeB plays an important role through its enzymatic activity not only for bacterial invasion, but it is also important for subversion of the immune responses for example by degrading antibodies [47] and antimicrobial peptides [12]. The present data demonstrates that $\mathrm{mSpeB}$ additionally enhances one of the important innate immune responses, the contact system, and does so via binding (and cleavage) of A1AT. These results also demonstrate a novel and important role of A1AT as modulator of an innate immune response in plasma. 
Under normal conditions A1AT circulates the blood at a concentration of approximately $25 \mu \mathrm{M}$ [48]. However, patients in sepsis display a marked elevation in the amount of A1AT [49]. At the same time plasma levels of HMWK, plasma kallikrein and factor XII are low in these patients [49]. After invasion the expression of mSpeB is reduced below the detection limit and would therefore not have an effect. However, since the blood concentration of A1AT is similar to the measured $\mathrm{K}_{\mathrm{d}}$, one would expect half of the A1AT to be scavenged by an administered bolus of mSpeB. Moreover, uninhibited $\mathrm{mSpeB}$ has the ability to cleave and inactivate A1AT which by itself would lead to depletion of A1AT. The ability of mSpeB to bind and cleave A1AT as demonstrated here would in turn free the newly generated kallikrein from inhibition by A1AT and thus result in an increased liberation of antimicrobial peptides from HMWK. Consequently, addition of exogenous A1AT to human plasma in vitro significantly increased the bacterial growth in plasma underscoring the relevance of the findings and the significance of the contact system in controlling bacterial infections in blood. Although A1AT is an important inhibitor of neutrophil proteases, increased concentration of A1AT during sepsis may have adverse effects by diminishing bacterial clearance by contact activation.

Scavenging by binding and cleavage of A1AT by mSpeB also induced a prolonged coagulation time. One of the hallmarks of severe S. pyogenes infections is hypercoagulation [50]. Addition of $\mathrm{mSpeB}$ to plasma caused a modest prolongation of the coagulation time after activation of the intrinsic pathways. Accordingly, possible scavenging of A1AT by mSpeB is not expected to worsen the hypercoagulative state seen in sepsis.

The conserved cysteine protease of S. pyogenes, SpeB, was observed to enhance the innate immune response against streptococci in plasma by non-covalent binding of A1AT. This led to boosting of an a priori activation of the contact system following bacterial contact and a subsequent increased generation of antimicrobial peptides. These findings demonstrate the benefits for the bacteria in down-regulation of SpeB during systemic infections and suggest that inhibition of A1AT during bacterial infections could have a beneficial therapeutic potential.

\section{ACKNOWLEDGEMENTS}

We thank Bertrand Raynal at the Pasteur Institute for performing analytical ultracentrifugation analysis and Charlotte O'Shea for the gift of SBED-labeled Spd1. The outstanding technical assistance of Signe A. Sjørup, Malgorzata Berlikowski, and Maria Baumgarten is greatly appreciated. We thank Sarah Nørklit Roed for helpful discussions. 


\section{REFERENCES}

1 Lamagni, T. L., Darenberg, J., Luca-Harari, B., Siljander, T., Efstratiou, A., HenriquesNormark, B., Vuopio-Varkila, J., Bouvet, A., Creti, R., Ekelund, K., Koliou, M., Reinert, R. R., Stathi, A., Strakova, L., Ungureanu, V., Schalen, C. and Jasir, A. (2008) Epidemiology of severe Streptococcus pyogenes disease in Europe. J. Clin. Microbiol. 46, 2359-2367

2 Carapetis, J. R., McDonald, M. and Wilson, N. J. (2005) Acute rheumatic fever. The Lancet. 366, 155-168

3 Johnson, D. R., Stevens, D. L. and Kaplan, E. L. (1992) Epidemiologic analysis of group A streptococcal serotypes associated with severe systemic infections, rheumatic fever, or uncomplicated pharyngitis. J. Infect. Dis. 166, 374-382

4 Sendi, P., Johansson, L., Dahesh, S., Van-Sorge, N. M., Darenberg, J., Norgren, M., Sjolin, J., Nizet, V. and Norrby-Teglund, A. (2009) Bacterial phenotype variants in group B streptococcal toxic shock syndrome. Emerg. Infect. Dis. 15, 223-232

5 Nizet, V. (2007) Understanding how leading bacterial pathogens subvert innate immunity to reveal novel therapeutic targets. J. Allergy Clin. Immunol. 120, 13-22

6 Tart, A. (2007) New understanding of the group A Streptococcus pathogenesis cycle. Trends Microbiol. 15, 318-325

7 Fae, K. C., da Silva, D. D., Oshiro, S. E., Tanaka, A. C., Pomerantzeff, P. M., Douay, C., Charron, D., Toubert, A., Cunningham, M. W., Kalil, J. and Guilherme, L. (2006) Mimicry in recognition of cardiac myosin peptides by heart-intralesional $\mathrm{T}$ cell clones from rheumatic heart disease. J. Immunol. 176, 5662-5670

8 Prinz, J. C. (2004) Disease mimicry--a pathogenetic concept for T cell-mediated autoimmune disorders triggered by molecular mimicry? Autoimmunity reviews. 3, 10-15 9 Todar, K. (2002) Streptococcus pyogenes In Todar's online textbook of bacteriology, University of Wisconsin-Madison Department of Bacteriology

10 Collin, M. and Olsen, A. (2003) Extracellular enzymes with immunomodulating activities: variations on a theme in Streptococcus pyogenes. Infect. Immun. 71, 2983-2992 11 Kapur, V., Majesky, M. W., Li, L. L., Black, R. A. and Musser, J. M. (1993) Cleavage of interleukin 1 beta (IL-1 beta) precursor to produce active IL-1 beta by a conserved extracellular cysteine protease from Streptococcus pyogenes. Proc. Natl. Acad. Sci. USA. 90, 7676-7680 12 Schmidtchen, A., Frick, I. M., Andersson, E., Tapper, H. and Bjorck, L. (2002) Proteinases of common pathogenic bacteria degrade and inactivate the antibacterial peptide LL37. Mol. Microbiol. 46, 157-168

13 Liu, T. Y. and Elliott, S. D. (1965) Streptococcal Proteinase: the Zymogen to Enzyme Transfromation. J. Biol. Chem. 240, 1138-1142

14 Kagawa, T. F., Cooney, J. C., Baker, H. M., McSweeney, S., Liu, M., Gubba, S., Musser, J. M. and Baker, E. N. (2000) Crystal structure of the zymogen form of the group A Streptococcus virulence factor SpeB: an integrin-binding cysteine protease. Proc. Natl. Acad. Sci. USA. 97, 2235-2240

15 Wang, C. C., Houng, H. C., Chen, C. L., Wang, P. J., Kuo, C. F., Lin, Y. S., Wu, J. J., Lin, M. T., Liu, C. C., Huang, W. and Chuang, W. J. (2009) Solution structure and backbone dynamics of streptopain: Insight into diverse substrate specificity. J. Biol. Chem. 284, 1095710967

16 Olsen, J., Dagil, R., Meinert Niclasen, L., Sørensen, O. and Kragelund, B. (2009) Structure of the mature streptococcal cysteine protease exotoxin $\mathrm{mSpeB}$ in its active dimeric form. J. Mol. Biol. 393, 693-703 
17 Trevino, J., Perez, N., Ramirez-Pena, E., Liu, Z., Shelburne, S. A., 3rd, Musser, J. M. and Sumby, P. (2009) CovS simultaneously activates and inhibits the CovR-mediated repression of distinct subsets of group A Streptococcus virulence factor-encoding genes. Infect. Immun. 77, 3141-3149

18 Ma, Y., Bryant, A. E., Salmi, D. B., McIndoo, E. and Stevens, D. L. (2009) vfr, a novel locus affecting cysteine protease production in Streptococcus pyogenes. J. Bacteriol. 191, 31893194

19 Neely, M. N., Lyon, W. R., Runft, D. L. and Caparon, M. (2003) Role of RopB in growth phase expression of the SpeB cysteine protease of Streptococcus pyogenes. J. Bacteriol. 185, 5166-5174

20 Lukomski, S., Sreevatsan, S., Amberg, C., Reichardt, W., Woischnik, M., Podbielski, A. and Musser, J. M. (1997) Inactivation of Streptococcus pyogenes extracellular cysteine protease significantly decreases mouse lethality of serotype M3 and M49 strains. J. Clin Invest. 99, 25742580

21 Kuo, C. F., Wu, J. J., Lin, K. Y., Tsai, P. J., Lee, S. C., Jin, Y. T., Lei, H. Y. and Lin, Y. S. (1998) Role of streptococcal pyrogenic exotoxin B in the mouse model of group A streptococcal infection. Infect. Immun. 66, 3931-3935

22 Lukomski, S., Montgomery, C. A., Rurangirwa, J., Geske, R. S., Barrish, J. P., Adams, G. J. and Musser, J. M. (1999) Extracellular cysteine protease produced by Streptococcus pyogenes participates in the pathogenesis of invasive skin infection and dissemination in mice. Infect. Immun. 67, 1779-1788

23 Cole, J. N., McArthur, J. D., McKay, F. C., Sanderson-Smith, M. L., Cork, A. J., Ranson, M., Rohde, M., Itzek, A., Sun, H., Ginsburg, D., Kotb, M., Nizet, V., Chhatwal, G. S. and Walker, M. J. (2006) Trigger for group A streptococcal M1T1 invasive disease. Faseb. J. 20, 1745-1747

24 Kazmi, S. U., Kansal, R., Aziz, R. K., Hooshdaran, M., Norrby-Teglund, A., Low, D. E., Halim, A. B. and Kotb, M. (2001) Reciprocal, temporal expression of SpeA and SpeB by invasive M1T1 group a streptococcal isolates in vivo. Infect. Immun. 69, 4988-4995 25 Graham, M. R., Virtaneva, K., Porcella, S. F., Barry, W. T., Gowen, B. B., Johnson, C. R., Wright, F. A. and Musser, J. M. (2005) Group A Streptococcus transcriptome dynamics during growth in human blood reveals bacterial adaptive and survival strategies. Am. J. Pathol. 166, 455-465

26 GraphPad. (2004) GraphPad Prism. GraphPad Software, Inc.

27 Böyum, A. (1968) Isolation of mononuclear cells and granulocytes from human blood isolation by one centrifugation and of granulocytes by combining centrifugation and sedimentation at $1 \mathrm{G}$. Scand. J. Clin. Lab. Invest. 97, 77-89

28 Loughman, J. A. and Caparon, M. (2006) Regulation of SpeB in Streptococcus pyogenes by $\mathrm{pH}$ and $\mathrm{NaCl}$ : a model for in vivo gene expression. J. Bacteriol. 188, 399-408

29 Frick, I. M., Akesson, P., Herwald, H., Morgelin, M., Malmsten, M., Nagler, D. K. and Bjorck, L. (2006) The contact system--a novel branch of innate immunity generating antibacterial peptides. EMBO J. 25, 5569-5578

30 Frick, I. M., Bjorck, L. and Herwald, H. (2007) The dual role of the contact system in bacterial infectious disease. Thromb. Haemostasis 98, 497-502

31 Nestoras, K., Mohammed, A. H., Schreurs, A. S., Fleck, O., Watson, A. T., Poitelea, M., O'Shea, C., Chahwan, C., Holmberg, C., Kragelund, B. B., Nielsen, O., Osborne, M., Carr, A. M. 
and Liu, C. Regulation of ribonucleotide reductase by Spd1 involves multiple mechanisms. Genes Dev. 24, 1145-1159

32 Finotti, P. and Pagetta, A. (1997) Albumin contamination of a purified human alpha 1antitrypsin preparation does not affect either structural conformation or the electrophoretic mobility of the inhibitor. Clin. Chim. Acta. 264, 133-148

33 Fasano, M., Curry, S., Terreno, E., Galliano, M., Fanali, G., Narciso, P., Notari, S. and Ascenzi, P. (2005) The extraordinary ligand binding properties of human serum albumin. IUBMB Life. 57, 787-796

34 Kagawa, T. F., O'Toole P, W. and Cooney, J. C. (2005) SpeB-Spi: a novel proteaseinhibitor pair from Streptococcus pyogenes. Mol. Microbiol. 57, 650-666

35 Wilczynska, M., Fa, M., Karolin, J., Ohlsson, P. I., Johansson, L. B. and Ny, T. (1997) Structural insights into serpin-protease complexes reveal the inhibitory mechanism of serpins. Nat. Struct. Biol. 4, 354-357

36 Huntington, J. A., Read, R. J. and Carrell, R. W. (2000) Structure of a serpin-protease complex shows inhibition by deformation. Nature 407, 923-926

37 Dementiev, A., Simonovic, M., Volz, K. and Gettins, P. G. (2003) Canonical inhibitorlike interactions explain reactivity of alpha1-proteinase inhibitor Pittsburgh and antithrombin with proteinases. J. Biol. Chem. 278, 37881-37887

38 Peterson, F. C., Gordon, N. C. and Gettins, P. G. (2000) Formation of a noncovalent serpin-proteinase complex involves no conformational change in the serpin. Use of $1 \mathrm{H}-15 \mathrm{~N}$ HSQC NMR as a sensitive nonperturbing monitor of conformation. Biochemistry 39, 1188411892

39 McConnell, D. J. (1972) Inhibitors of kallikrein in human plasma. J. Clin. Invest. 51, $1611-1623$

40 Heeb, M. J. and Griffin, J. H. (1988) Physiologic inhibition of human activated protein C by alpha 1-antitrypsin. J. Biol. Chem. 263, 11613-11616

41 Janciauskiene, S. (2001) Conformational properties of serine proteinase inhibitors (serpins) confer multiple pathophysiological roles. Biochim. Biophys. Acta. 1535, 221-235 42 van der Poll, T., Levi, M., Nick, J. A. and Abraham, E. (2005) Activated protein C inhibits local coagulation after intrapulmonary delivery of endotoxin in humans. Am. J. Respir. Crit. Care Med. 171, 1125-1128

43 Esmon, C. T., Fukudome, K., Mather, T., Bode, W., Regan, L. M., Stearns-Kurosawa, D. J. and Kurosawa, S. (1999) Inflammation, sepsis, and coagulation. Haematologica 84, 254-259 44 Chaussee, M. S., Phillips, E. R. and Ferretti, J. J. (1997) Temporal production of streptococcal erythrogenic toxin B (streptococcal cysteine proteinase) in response to nutrient depletion. Infect. Immun. 65, 1956-1959

45 Chatellier, S., Ihendyane, N., Kansal, R. G., Khambaty, F., Basma, H., Norrby-Teglund, A., Low, D. E., McGeer, A. and Kotb, M. (2000) Genetic relatedness and superantigen expression in group A streptococcus serotype M1 isolates from patients with severe and nonsevere invasive diseases. Infect. Immun. 68, 3523-3534

46 Kansal, R. G., McGeer, A., Low, D. E., Norrby-Teglund, A. and Kotb, M. (2000) Inverse relation between disease severity and expression of the streptococcal cysteine protease, SpeB, among clonal M1T1 isolates recovered from invasive group A streptococcal infection cases. Infect. Immun. 68, 6362-6369

47 Collin, M. and Olsen, A. (2001) Effect of SpeB and EndoS from Streptococcus pyogenes on human immunoglobulins. Infect. Immun. 69, 7187-7189 
48 Yang, P., Wentzlaff, K. A., Katzmann, J. A., Marks, R. S., Allen, M. S., Lesnick, T. G., Lindor, N. M., Myers, J. L., Wiegert, E., Midthun, D. E., Thibodeau, S. N. and Krowka, M. J. (1999) Alpha1-antitrypsin deficiency allele carriers among lung cancer patients. Cancer Epidemiol. Biomarkers Prev. 8, 461-465

49 Smith-Erichsen, N., Aasen, A. O., Gallimore, M. J. and Amundsen, E. (1982) Studies of components of the coagulation systems in normal individuals and septic shock patients. Circulatory shock. 9, 491-497

50 Bisno, A. L. and Stevens, D. L. (1996) Streptococcal infections of skin and soft tissues. N. Engl. J. Med. 334, 240-245 


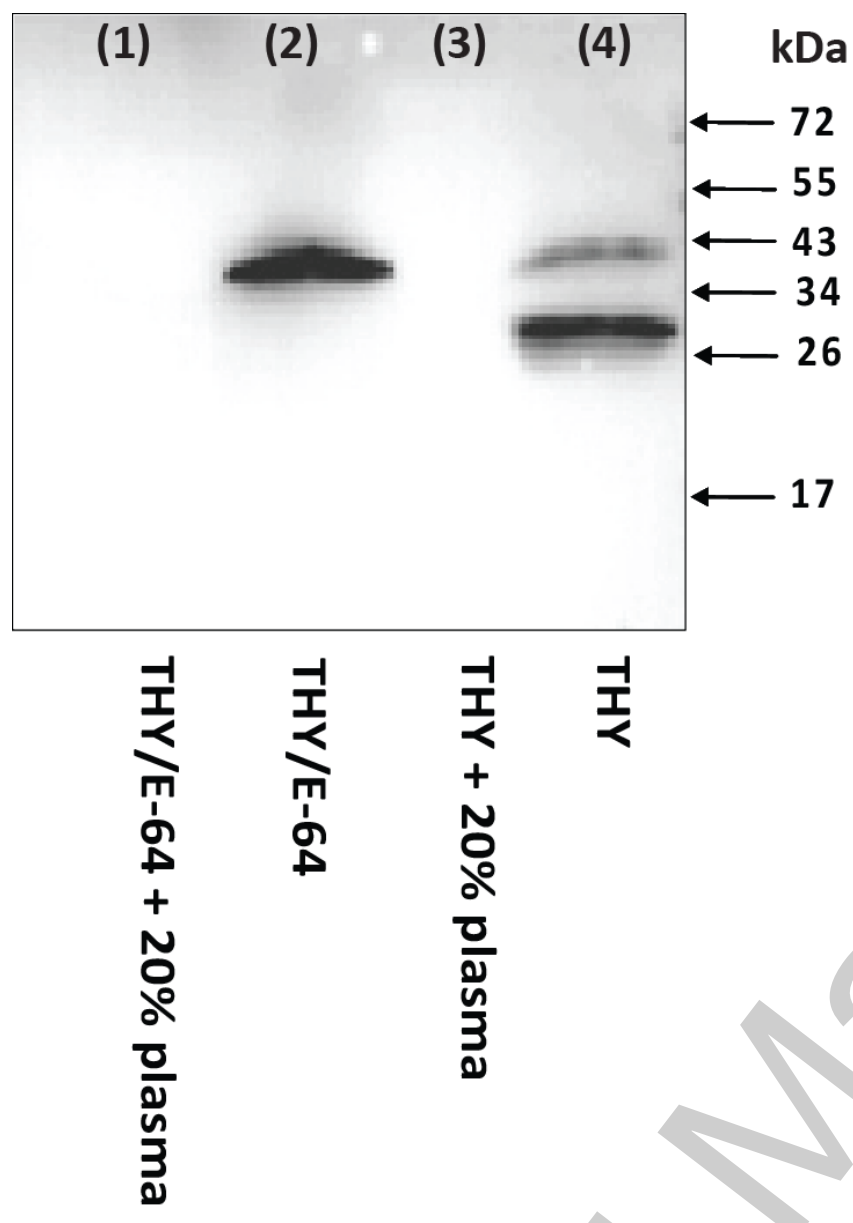

Figure 1: Plasma influences the amount of $\mathrm{mSpeB}$ secreted by Streptococcus pyogenes. Bacteria strain ALAB 49 was grown and harvested in stationary phase from THY media supplemented with (lanes 1 and 3) or without (lanes 2 and 4) 20\% (v/v) of human plasma. The harvested cells were normalized by $\mathrm{OD}(\mathrm{OD}=1)$ and directly analyzed by Western blot. The presence of SpeB was investigated by Western blot showing the presence of enzyme only in the absence of plasma. In the presence of the protease inhibitor E64 (lane 1 and 2), the zymogen protein at $40 \mathrm{kDa}$ was detected (lane 2 ) and in the absence of E64, this was matured also to active enzyme mSpeB at $28 \mathrm{kDa}$ (lane 4). The presence of SpeB was irrespective of the activity of the enzyme (compare lanes 2 and 4). Molecular weight markers are indicated to the right. 
A

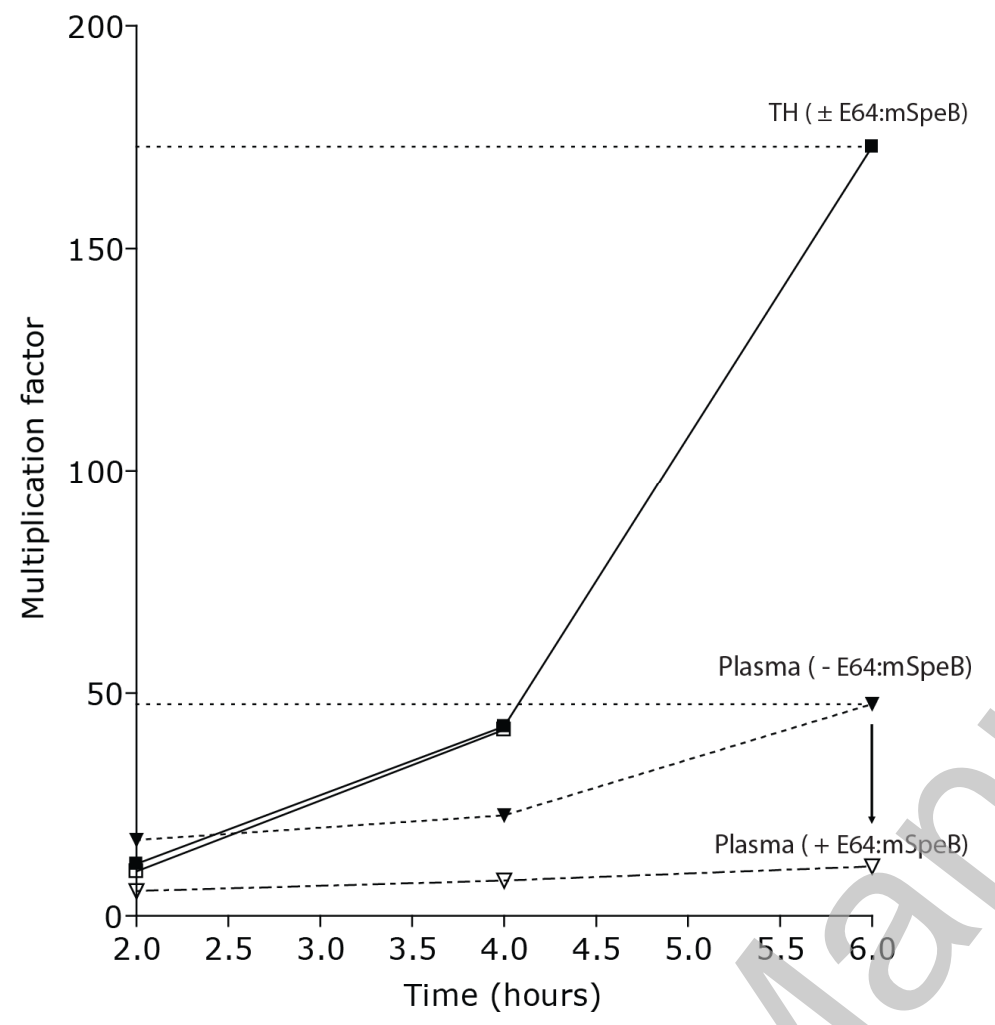

B

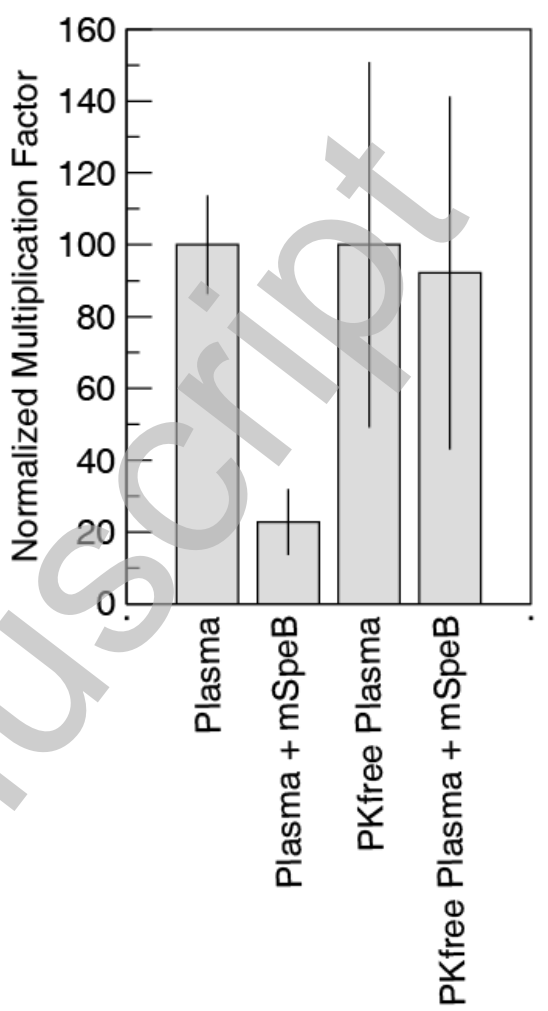

Figure 2: Inhibition of bacterial growth by $\mathbf{m S p e B}$. A) Growth of. S. pyogenes AP1 in TH or in plasma with or without E64-inhibited mSpeB present. S. pyogenes AP1 bacteria were cultivated in TH media $(--\leftarrow)$ ) or in undiluted human plasma $(\rightarrow-$ (dotted line); $\rightarrow$ (dashed line)). Filled symbols represent growth without $\mathrm{mSpeB}$ and open symbols represent growth with E64-inhibited $\mathrm{mSpeB}$ added. The two vertical dotted lines show growth after 6 hours in TH-media (upper line) and plasma (lower line) and are drawn to guide the eye. Significantly reduced growth was seen when E64-inhibited $\mathrm{mSpeB}$ were added to the plasma $\left({ }^{*}=\mathrm{p}<0.05\right)$. This effect was not seen when E64inhibited $\mathrm{mSpeB}$ was added to TH-media. Cultures were evaluated at the same time points after incubation, they were in the same growth phase (stationary) and OD was measured, standardized and dilution made from this. B) Effect of $\mathrm{mSpeB}$ on bacterial growth in prekallikrein deficient (PKfree) plasma compared to ordinary plasma. The normalized effects are relative to growth under non-mSpeB conditions. mSpeB significantly reduced bacterial growth in plasma with little or no effect of $\mathrm{mSpeB}$ on growth of AP1 in PKfree plasma . 
A
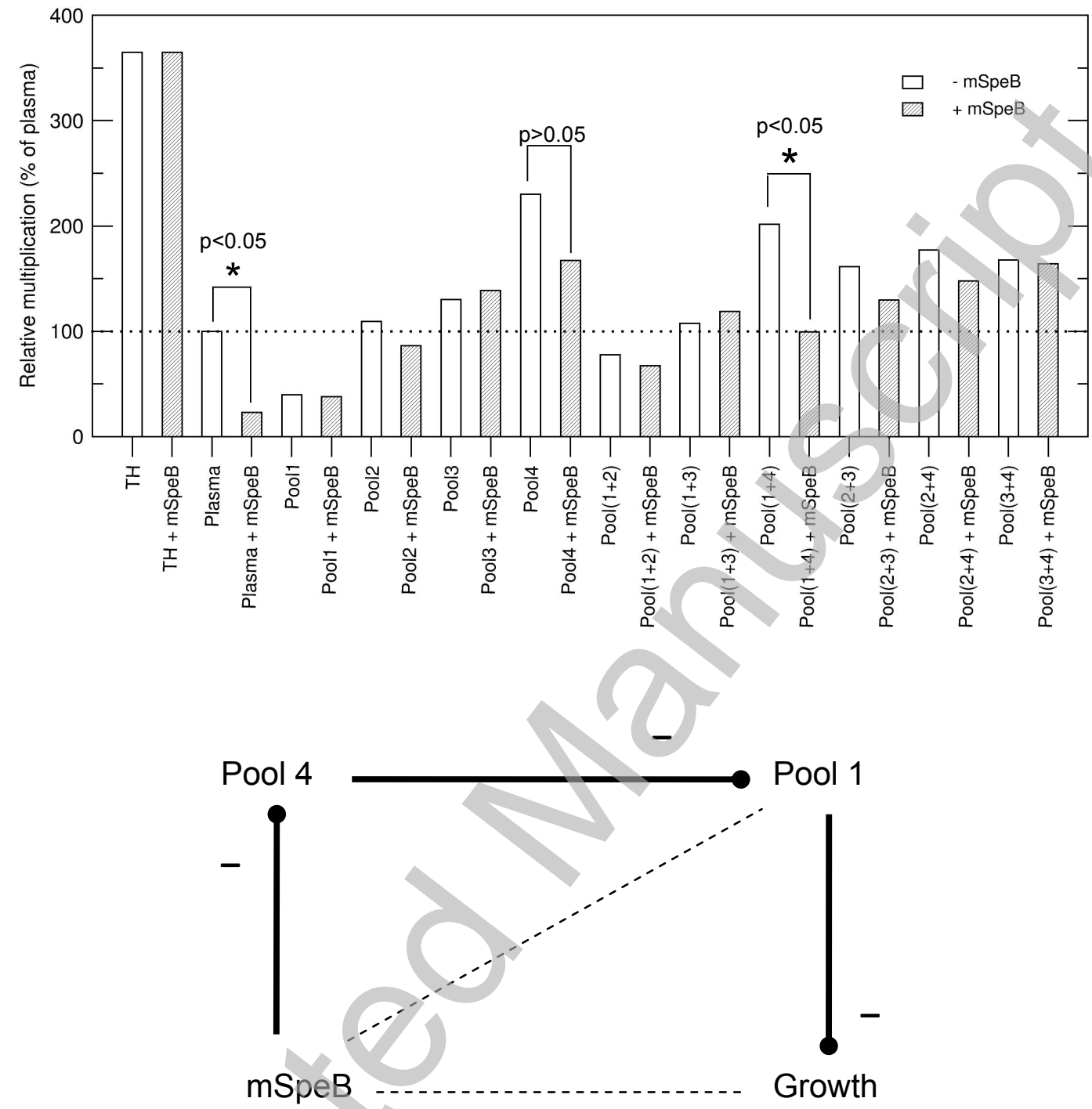

Figure 3: $\mathrm{mSpeB}$ inhibits bacterial growth through interaction with plasma proteins. A) Growth of SP strain AP1 in selected plasma protein pools obtained from gel filtration of whole plasma compared to growth in TH and plasma after 6 hours of incubation. Growth has been normalized to growth in plasma and the dotted line indicates $100 \%$ (equal to growth in plasma). Poor growth was seen for plasma pool 1 (high molecular weight plasma proteins) regardless of addition of E64-inhibited mSpeB (Pool $1+$ SpeB). Plasma pool 4 (low molecular weight plasma proteins) showed a growth rate comparable to growth in TH media with a reduction in growth, although insignificant, with addition of E-64-inhibited mSpeB ( $p>0.05$ ). Pooled plasma pools 1 and 4 (Pool 1\&4) showed significant E-64-inhibited mSpeB dependent reduction in growth after 6 hours $\left({ }^{*}=\mathrm{p}<0.05\right)$. B) A scheme delineating the primary conclusion from the growth inhibition assays shown in A). Addition of E64-inhibited $\mathrm{mSpeB}$ has no significant effect on 
growth in the presence of any of pools 1 through 3 and only a modest growth inhibitory effect when combined with pool 4. Adding pool 4 to pool 1 abolishes the growth inhibitory effect of pool 1 but shows that inhibition is impeded - at least in part - by the addition of the E64-mSpeB complex. Dashed lines indicate no effect; solid lines with black ball indicate an inhibitory effect. 
A

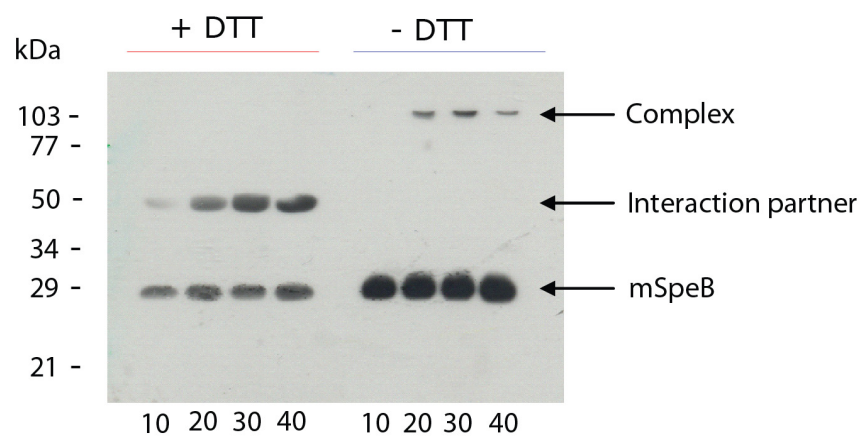

Irradiation time $(\mathrm{min})$

B

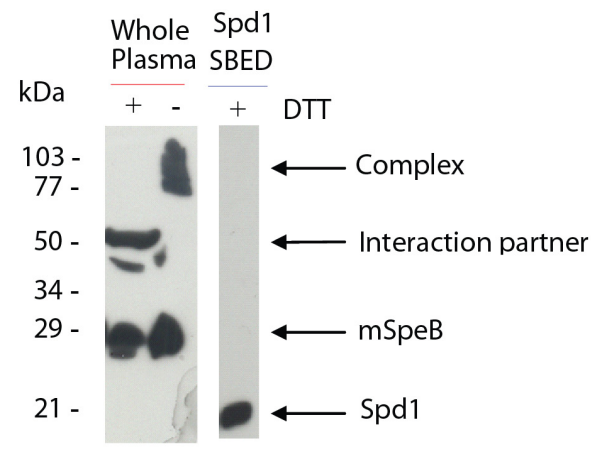

C

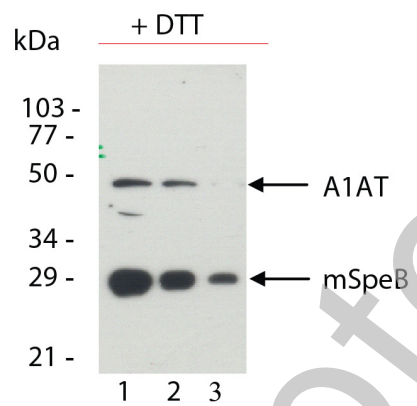

Figure 4: Identification of plasma interaction partners. Western blots of cross-linking experiment with SBED-labeled $\mathrm{mSpeB}$. A) Western blot of cross-linking experiment using SBED-labeled $\mathrm{mSpeB}$ and plasma pool 4 (low molecular weight proteins from human plasma). Labeling efficiency was tested at $365 \mathrm{~nm}$ and $19 \mu \mathrm{M} \mathrm{mSpeB}$ at different irradiation times. One single band of approximately $50 \mathrm{kDa}$ was identified indicating one single interaction partner. The samples were run with and without reducing agent with the non reduced samples revealing the complex between $\mathrm{mSpeB}$ and the interaction partner. B) Western blot of cross-linking experiment of SBED-labeled mSpeB with whole human plasma or with Spd1. The cross-linking experiment showed one major band and one minor when incubating mSpeB-SBED with whole plasma. Spd1SBED did not cross-link to any protein in whole plasma indicating that the affinity of 
$\mathrm{mSpeB}$ for any partner does not originate from the photo label itself. C) Western blot of cross-linking between purified A1AT and SBED-labeled mSpeB. Commercially purchased A1AT cross-linked to SBED-labeled mSpeB $(40 \mu \mathrm{M})$ at different ratios. Lane 1: (1:0.5) ratio of mSpeB-SBED:A1AT. Lane 2: 1:1 ratio of mSpeB-SBED:A1AT. Lane 3: 1:5 ratio of mSpeB-SBED:A1AT (uncorrected for volume changes). Without the presence of other plasma proteins to assist the interaction, interaction of the two proteins is still possible. 


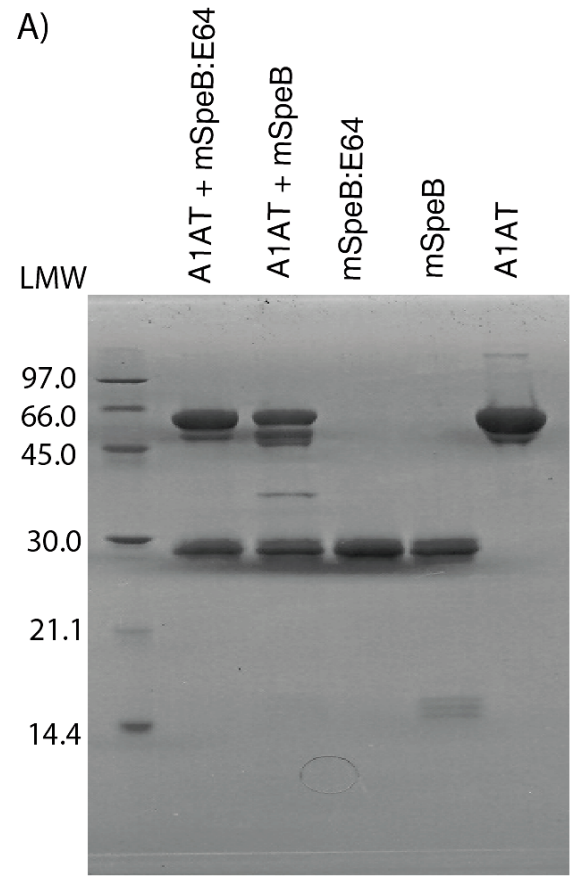

B)

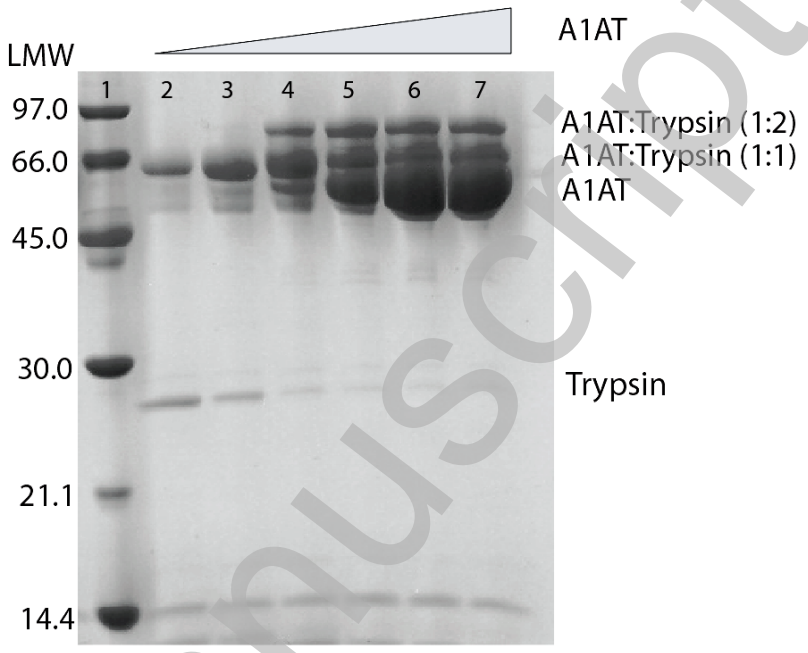

Figure 5: mSpeB degrades A1AT without formation of a covalent complex. Commercially purchased A1AT was incubated for 6 hours at RT with either active or E64-inhibited mSpeB at 1:1 molar ratios. The reaction mixtures were analyzed by nonreducing SDS-PAGE and stained with coomassie brilliant blue. A) E64-inhibited and active $\mathrm{mSpeB}$ mixed with A1AT are shown in lane 1 and 2, respectively. Lane 3, 4 and 5 show E64-inhibited $\mathrm{mSpeB}$, active $\mathrm{mSpeB}$ and A1AT run separately. LMW is shown in the left side of the SDS-PAGE gel. B) A1AT and trypsin mixed forms covalent complex. From lanes left to right increasing amounts of A1AT are added while the trypsin concentration is kept constant. From lane 4 to 7 a A1AT:trypsin 2:1 complex is formed. LMW is shown to the left. 


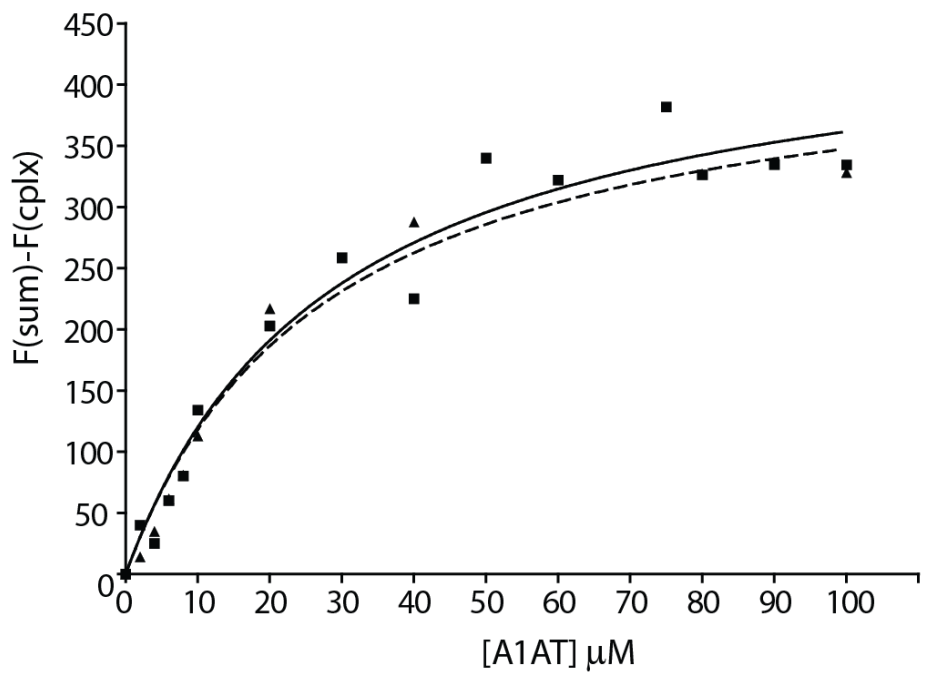

Figure 6: A1AT and $\mathrm{mSpeB}$ interact specifically - $K_{d}$ determination using fluorescence spectroscopy. The interaction between $\mathrm{mSpeB}$ and A1AT was examined using fluorescence spectroscopy. $10 \mu \mathrm{M}$ mSpeB was incubated with 0-100 $\mu \mathrm{M}$ A1AT in PBS pH 7.4 at room temperature and the summed emission curve was compared to the emission curve of the complex sample (see experimental procedures). The $\mathrm{K}_{\mathrm{d}}$ for binding between E64-inhibited $\mathrm{mSpeB}$ and $\mathrm{A} 1 \mathrm{AT}$ was determined to be $29 \pm 7 \mu \mathrm{M}$ (solid line) from a non-linear fit to the equation expecting one binding site $\left(Y=\left(B \max { }^{*} x\right) /\left(K_{d}\right.\right.$ $+x)$ ) using GraphPad Prism 4. Two independent measurements are shown at two different E64-concentrations, 1:0.8 as filled squares and 1:2 as filled triangles. The value of $\mathrm{K}_{\mathrm{d}}$ is the average of the two measurements and the error represents the goodness of the fit. 


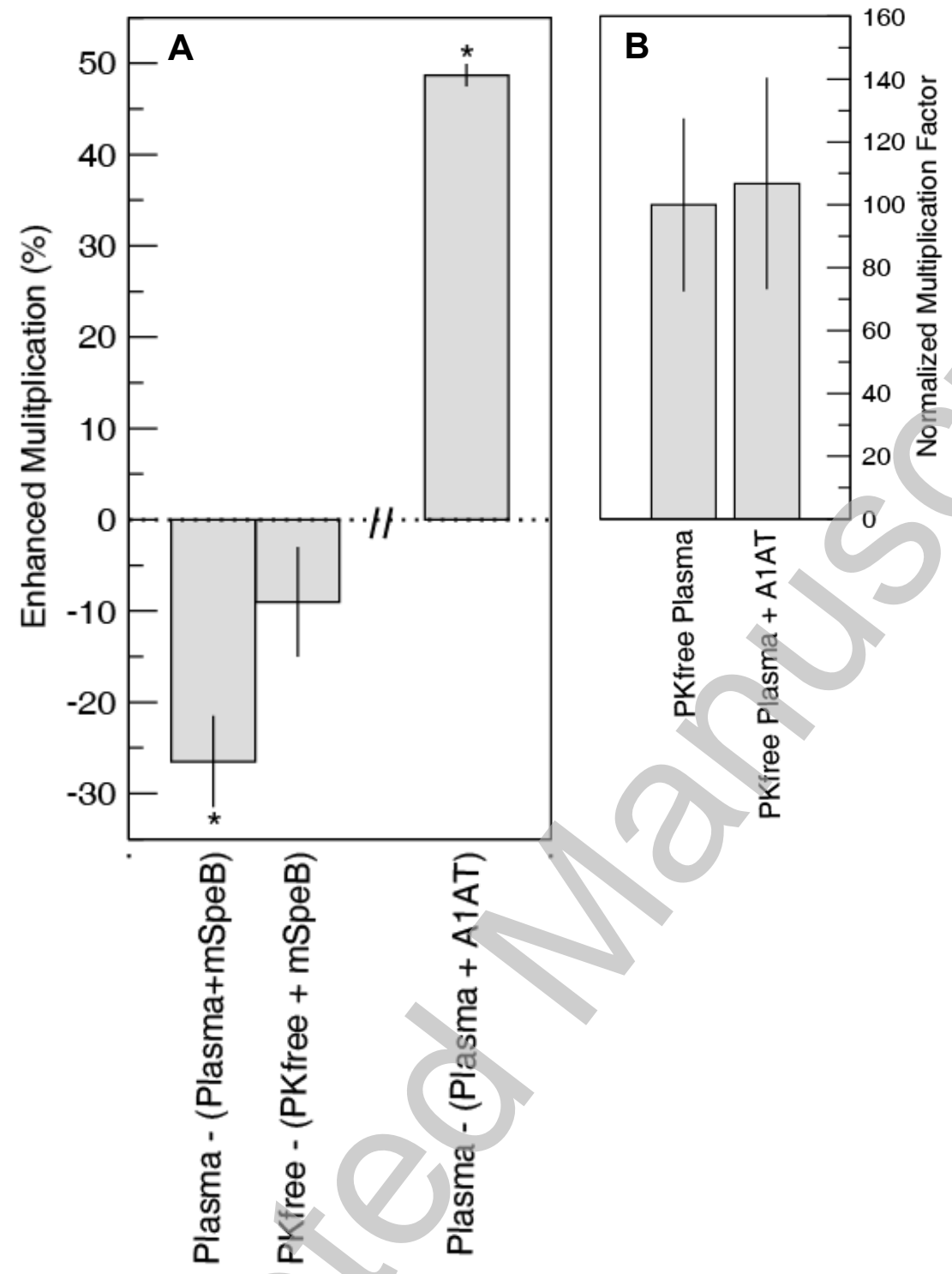

Figure 7: A1AT knocks out the contact system and leads to enhanced bacterial growth. A) Significantly enhanced growth was seen when A1AT at $14.4 \mu \mathrm{M}$ were added to human plasma leading to enhanced bacterial multiplication $\left({ }^{*}=\mathrm{p}<0.05\right)$. Growth of AP1 bacteria was normalized to growth in human plasma without addition of A1AT. For comparison the effects from E64-inhibited mSpeB on growth in human plasma and in prekallikrein-free plasma are shown. The effects were normalized to growth in the absence of E64-inhibited mSpeB. S. pyogenes AP1 bacteria were cultivated and growth monitored after 6 hours. B) No effect on growth was observed when A1AT at $14.4 \mu \mathrm{M}$ was added to prekallikrein-free plasma. Multiplication after 6 hours were measured and normalized to growth in prekallikrein-free plasma added PBS. 


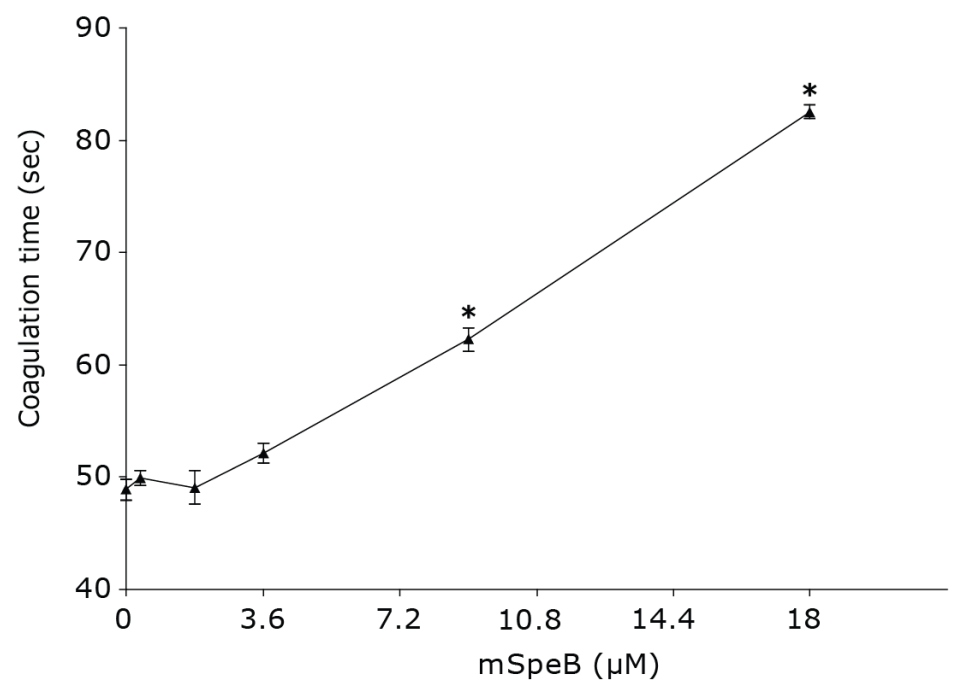

Figure 8: $\mathrm{mSpeB}$ induces increased blood coagulation time through the contact system. The coagulation time of human citrate plasma was examined through the intrinsic pathway of coagulation. The time to form a clot was significantly prolonged after incubation with E64-inhibited $\mathrm{mSpeB}(\mp)$ at concentrations of $9 \mu \mathrm{M}\left({ }^{*}=\mathrm{p}<0.05\right)$. 
A

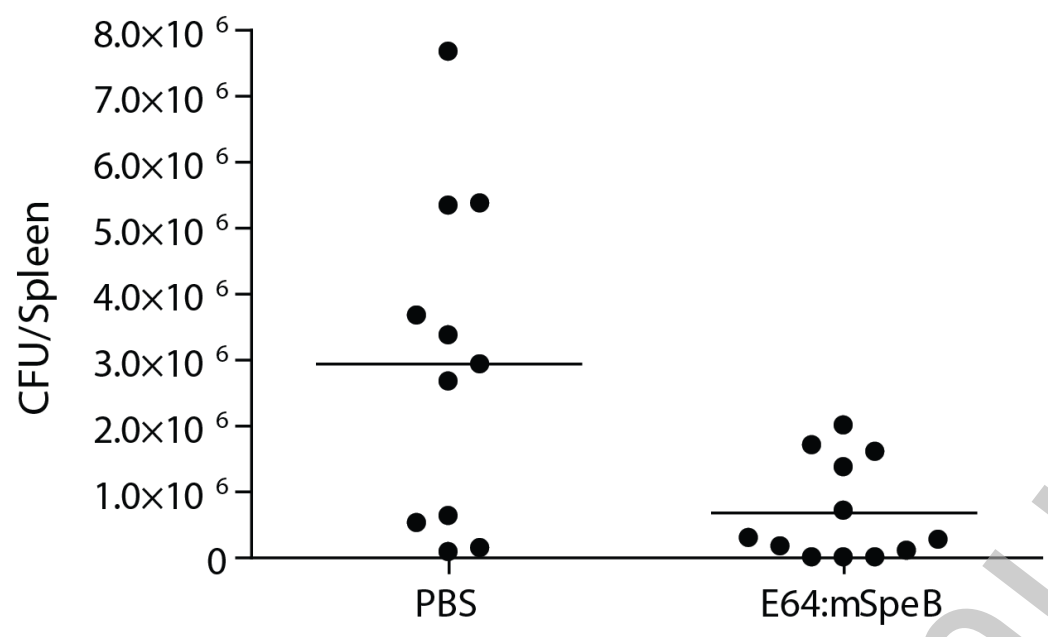

B

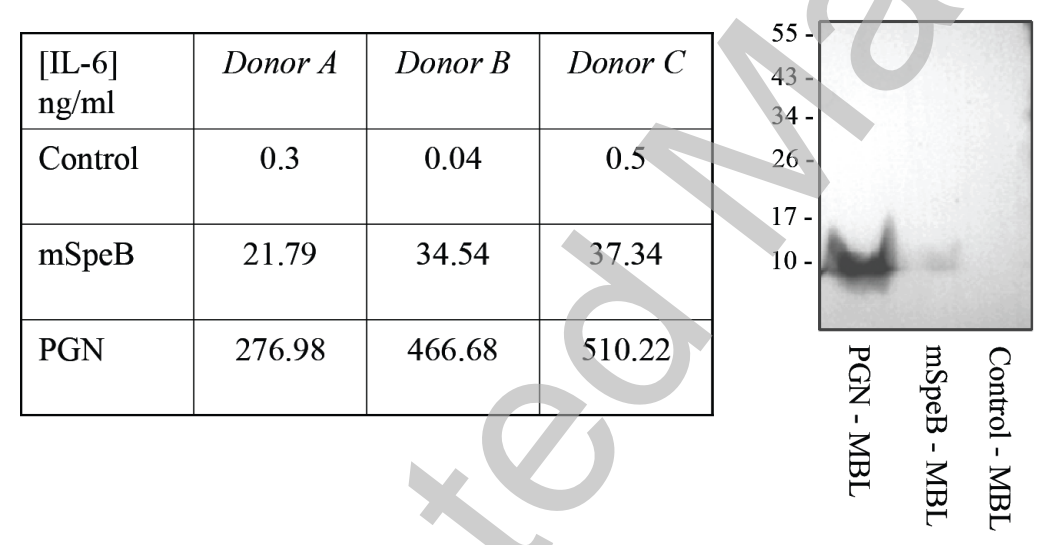

Figure 9: SpeB decreased bacterial dissemination of $S$. pyogenes in vivo and had limited proinflammatory activity. A) Limited systemic spread of bacteria in vivo was observed. Male Balb/C mice 8-11 weeks of age were injected i.p. with S. pyogenes AP1 bacteria $\left(1 \times 10^{6} \mathrm{CFU}\right)$, followed by i.p. injection of $\mathrm{PBS}(\mathrm{E} 64)$ or $\mathrm{mSpeB}(\mathrm{E} 64)$ (50 $\mu \mathrm{g}$ /animal). The mice were sacrificed 18 hours after the last injection and the total number of CFU in the spleen was determined by serial dilution on blood agar plates. The number of CFU in the spleen of the mice administered with mSpeB was significantly lower than in the control group $(\mathrm{P}=0.027)$. The $\mathrm{P}$-value was determined using the two-tailed t-test. Bars represent the mean value in each group. B) Limited proinflammatory activity of SpeB. Mononuclear cells harvested from blood (MBL) were 
stimulated with $10 \mu \mathrm{g} / \mathrm{ml}$ peptidoglycan (PGN), or $10 \mu \mathrm{g} / \mathrm{ml}$ E64 inhibited mSpeB (mSpeB). After four days the medium was harvested and analyzed for IL-6 and IL-8 production. Left: IL-6 production monitored by ELISA. Limited IL-6 production was found in mSpeB stimulated MBLs compared to those stimulated with peptidoglycan.

Right: IL-8 production was analyzed by Western blot where mSpeB was shown to be a poor inducer of IL-8 production compared to peptidoglycan (a representative experiment out of three is shown). 